\title{
Characterisation of thrombocytes in Osteichthyes
}

\author{
Michał Stosik ${ }^{1}$, Beata Tokarz-Deptuła ${ }^{2}$, Wiesław Deptuła ${ }^{3}$ \\ ${ }^{1}$ Department of Microbiology and Genetics, Faculty of Biological Sciences, \\ University of Zielona Góra, 65-516 Zielona Góra, Poland \\ ${ }^{2}$ Department of Immunology, ${ }^{3}$ Department of Microbiology, \\ Faculty of Biology, University of Szczecin, 70-453 Szczecin, Poland \\ m.stosik@wnb.uz.zgora.pl
}

Received: August 21, $2018 \quad$ Accepted: March 4, 2019

\begin{abstract}
Thrombocytes in vertebrates other than mammals, inter alia in fish, are analogues of platelets in mammals. In Osteichthyes, these cells take part in haemostatic processes, including aggregation and release reactions in cases of blood vessel damage, and in the immune response development as well. This paper discusses the development of thrombocytes in Osteichthyes, taking into account the need to make changes to the concept of grouping progenitor cells as suggested in the literature. The following pages present the morphological and cytochemical properties of thrombocytes as well as their defence functions, and also point out differences between thrombocytes in fish and platelets in mammals. The paper further highlights the level of thrombocytes' immune activity observed in fish and based on an increased proportion of these cells in response to antigenic stimulation, on morphological shifts towards forms characteristic of dendritic cells after antigenic stimulation and on the presence of surface structures and cytokines released through, inter alia, gene expression of TLR receptors, MHC class II protein-coding genes and pro-inflammatory cytokines. The study also points out the need to recognise thrombocytes in Osteichthyes as specialised immune cells conditioning non-specific immune mechanisms and playing an important role in affecting adaptive immune mechanisms.
\end{abstract}

Keywords: thrombocytes in fish, development, morphology, cytochemistry, defence functions.

\section{Introduction}

Thrombocytes in fish, amphibians, reptiles and birds are analogues of platelets in mammals, organisms classified into the same taxonomic group of vertebrates $(4,5,11,24,25)$. It should also be added that in invertebrates, the cells that are functionally similar to vertebrate (but not mammalian) thrombocytes and to mammalian platelets are the nucleated haemocytes circulating in haemolymph, also called immunocytes (4). Thrombocytes in Osteichthyes have a nucleus and, functionally, they are cells corresponding to platelets in mammals but, with regard to the origin of these cells, it should be underlined that megakaryocytes from which mammalian platelets develop are absent in Osteichthyes $(11,13,14)$. Thrombocytes develop in the head kidney (pronephros), an analogue of bone marrow in mammals (14), as myeloid cells in the process of thrombopoiesis and as part of myelopoiesis, just like monocytes/macrophages (monopoiesis), granulocytes (granulopoiesis) or erythrocytes (erythropoiesis) do. The precursor or parent cells for the cells mentioned above and for lymphoid cells are haematopoietic stem cells (HSCs) and haematopoietic progenitor cells (HPCs) (14). In Osteichthyes, these types of cells develop in the hind kidney (mesonephros), a part of an organ having an excretory function where the key role in the formation of cells of this subpopulation is played by renal tubules $(6,19,20,21)$. In Osteichthyes, thrombocytes take part in haemostatic processes, including aggregation and release of endothrombocytic granule components in cases of blood vessel damage, and in the immune response development as part of innate and adaptive immune mechanisms (4, 5, 7, 24, $25,36,41)$. The morphological, cytochemical, and other properties of thrombocytes in Osteichthyes, as defined and characterised above, were an object of interest and research years ago. These cells were of course examined with the degree of thoroughness that was possible at that time and conditioned by, inter alia, 
available research techniques $(7,14,22,32,35-41,44$, 45). Among the mentioned areas of thrombocytes' biological activity, their involvement in the immune response development as important mediators attracts special interest. Research has revealed, inter alia, involvement of thrombocytes in phagocytosis, including the intracellular process of killing bacteria (2, $7,24,25,36,37,40,41$ ), and expression of the pathway components of the major histocompatibility complex (MHC la, $\beta 2 \mathrm{~m}$, LMP, TAP1 \& TAP2 and of MHC class IIB molecules) $(5,22,24,25)$. The research has thus indicated thrombocytes' likely role as antigenpresenting cells (APCs).

\section{Development of thrombocytes in Osteichthyes}

Osteichthyes kidneys were found to contain cells of the haematopoietic stem cell (HSC) and haematopoietic progenitor cell (HPC) subpopulations as well as common myeloid progenitor (CMP) cells which focus on developing monocytes/macrophages and granulocytes through granulocyte/macrophage progenitor (GMP) cells, and thrombocytes and erythrocytes through thrombocytic/erythrocyte progenitor (TEP) cells that are analogues of megakaryocyte/erythrocyte progenitor (MEP) cells in mammals $(11,13,14)$. No megakaryocytes defined as cells with specific functional properties that are present in higher vertebrates, i.e. the mammals, have been found in fish $(11,42)$. In mammals, the proliferation and differentiation of all cells named above are controlled by activity of the cytokines crucial for the maintenance and differentiation of CMPs which include, apart from the stem cell factor (SCF), the macrophage colony-stimulating factor (M-CSF), granulocyte colony-stimulating factor (G-CSF) and erythropoietin (EPO), while for megakaryocytes and platelets, CMPs include thrombopoietin (TPO) together with the c-Mpl receptor for this cytokine (14). Affecting the population of MEP cells in mammals, TPO initiates intracellular signalling cascades controlled by transcription factors and leads to the final differentiation of MEP cells (14) (Fig. 1a).

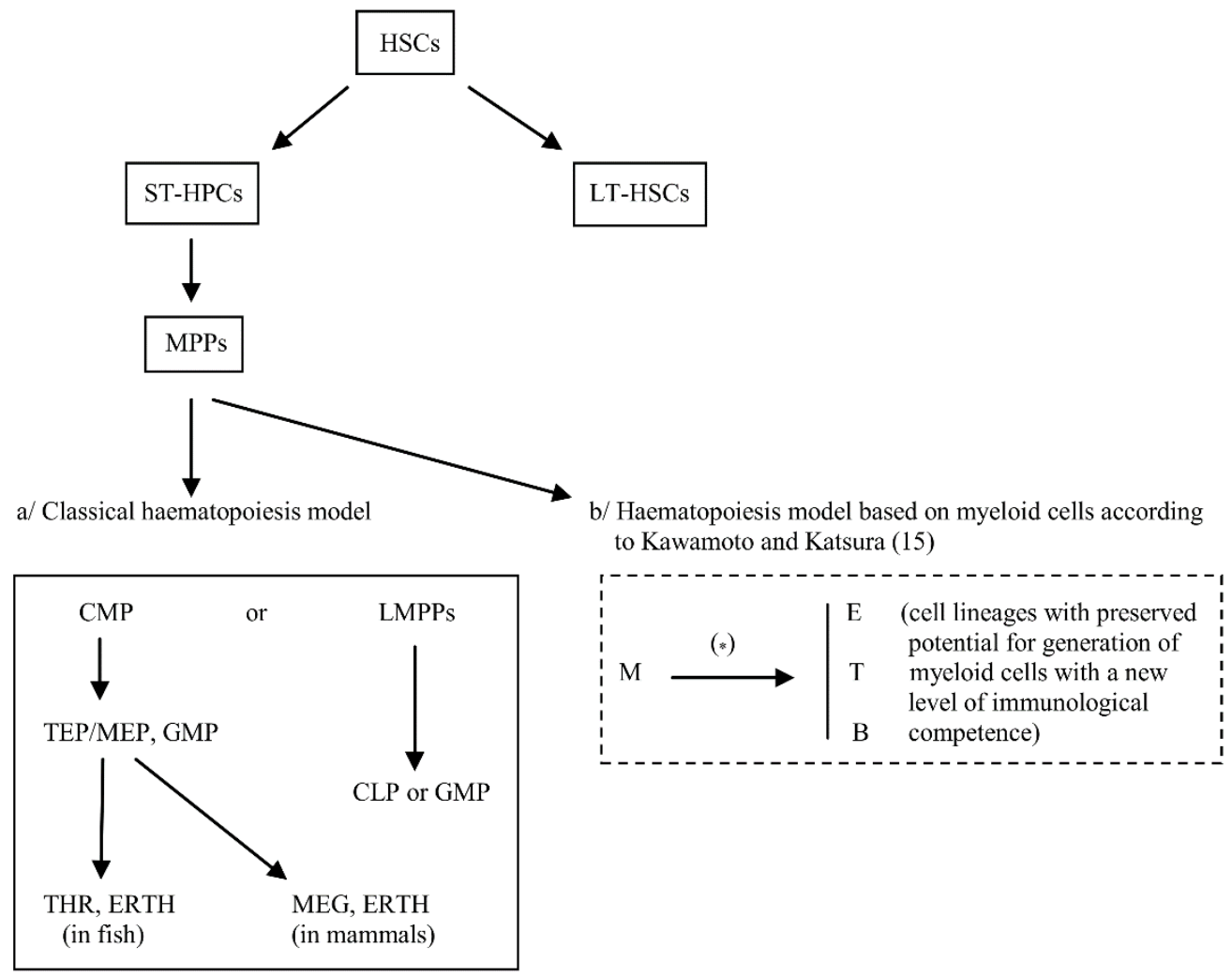

Fig. 1. The classical haematopoiesis model and another one, based on myeloid cells, as proposed by Kawamoto and Katsura (16). HSCs - haematopoietic stem cells, LT-HSCs - long term HSCs, HSC populations ability to self-renew, ST-HPCs - short term haematopoietic progenitor cells HPCs, limited ability to self-renew, MPPs - multi-potent progenitors, no ability to selfrenew,

a/ CMP - common myeloid progenitor, LMPPs - lymphoid-myeloid primed multi-potent progenitor, MEP megakaryocyte/erythrocyte progenitor, in mammals, TEP - thrombocytic/erythrocyte progenitor, in vertebrates other than mammals, GMP - granulocyte/macrophage progenitor, CLP - common lymphoid precursor, THR - thrombocytes in fish, MEG - megakaryocytes in mammals, ERTH - erythrocytes in mammals and fish,

b/ M - prototype of blood cells (prototype myeloid cell lineage/prototype of haematopoietic cells which covering cells that phagocytise monocytes/macrophages, granulocytes and thrombocytes, featuring basic defence mechanisms, such as phagocytic activity and mobility), E - cells representing a specialised erythroid cell lineage, $\mathrm{T}$ - cells representing a specialised T-cell lineage, B - cells representing a specialised B-cell lineage, ${ }^{(*)}$ evolutionary events 
Here, it is worth mentioning the need to make changes to the classic concept of grouping common myloid precursor (CMP) and common lymphoid precursor (CLP) cells, as suggested by Kawamoto and Katsura (16) as well as by Kawamoto et al. (15). The changes would consist in placing all types of cells in the myeloid cell group (M) as haematopoietic cell prototypes of specialised blood cells represented by erythroid cells (E) as well as T- and B- lymphocytes (T, B) (Fig. 1b). These authors $(15,16)$ point out that it is justified by, inter alia, classifying phagocytosis as the primary function of CMP and MEP cells in ancestors of vertebrates which is likely to be a vestigial feature of platelets in higher vertebrates, given that the specialised cells reach a new level of activity, whereas the former basic function, e.g. the ability to phagocytise is modified to a lesser or greater extent or is disabled. An example can be the evolution of phagocytic activity of Blymphocytes in fish which decreases but is still maintained, whereas the ability of these cells to recognise specific antigens is a newly acquired property $(15,16,24,46)$. Another example is the evolutionarily likely phagocytic activity of nucleated fish red blood cells (RBCs) that have pattern recognition receptors (PRRs) and are capable of recognising pathogen associated molecular patterns (PAMPs) and of responding to them by means of released factors similar to cytokines, such as interferon- $\gamma$ (IFN- $\gamma$ ) or interferon- $\alpha$ (IFN- $\alpha$ ). This suggests that the cells possibly take part in immune response reactions and are capable of compensating for evolutionary immune deficits in fish $(27,28)$. Research on Osteichthyes has revealed an effect of TPO on the differentiation of progenitor cells focusing on developing thrombocytes (10-12, 14, 42). In goldfish (Carassius auratus), increased mRNA levels of cd41 for cluster of differentiation CD41, a marker for thrombocytes and c-Mpl, classified into surface thrombopoietic markers for progenitor cells and transcription factors GATA1 and LMO2, crucial for thrombopoiesis in fish and for the regulation of development of both erythrocytes and thrombocytes, have been found as response to recombinant goldfish TPO (rgTPO) in synergistic action with recombinant goldfish Kit ligand A - kitla (rgKITLA), called stem cell factor (SCF) - a growth factor crucial for the maintenance and differentiation of stem cells. Cell colonies of the thrombopoietic lineage, formed in the presence of $\mathrm{rgTPO}$ and $\operatorname{rgKITLA}$, contained immature cells and thrombocytes similar to mammalian megakaryocytes in terms of morphology. It must, however, be stressed that rgTPO used alone did not induce any significant proliferating response of TEP cells $(11,14)$. The significance of TPO in the focused development of thrombocytes has also been demonstrated in research on embryos of the zebrafish (Danio rerio), where it was reflected in an increase in the numbers of $\mathrm{cmyb}^{+}$cells (markers for HSCs, proto-oncogenes showing strong expression in immature haematopoietic cells) and of $\mathrm{CD} 1^{+}$(42). Svoboda et al. (42) showed that fish, just as other non mammalian vertebrates, have TEP and CD4 $1^{+}$cells (Fig. 1), functional analogues of which are progenitor cells of megakaryocytes and erythrocytes in mammals (MEPs). These authors (42) have also pointed to the evolutionary relationship between the processes of differentiation of thrombocytes and platelets in vertebrates, suggesting that megakaryocytes, which are a source of platelets in mammals, have evolved from thrombocytes of non mammalian vertebrates and that they are homologues (Fig. 2), as can be seen for example from the number of cell divisions during the differentiation of TEPs in the zebrafish, as well as from the clear link between this process and the one observed during the differentiation of MEPs in mammals.

According to a study by Svoboda et al. (42), the CD41 marker is particularly specific to thrombocyte and erythrocyte progenitor cells. CD41 in a complex with CD61 has also been found in the channel catfish (Ictalurus punctatus) and the blue catfish (Ictalurus furcatus) (29). It is worth pointing out in the light of these data that in mammals, CD41 and CD61 receptors are used to identify megakaryocytic precursors, megakaryocytes and platelets, and that the CD41/CD61 complex (also known as $\alpha \mathrm{Ilb} / \beta 3$ or glycoprotein IIb/IIIa) contributes to the activation and aggregation of platelets (29). Research on the carp (Cyprinus carpio) has also revealed that recombinant carp TPO (rcTPO) induced the formation of $\mathrm{c}-\mathrm{Mpl}^{+}$and $\mathrm{CD} 41^{+}$ thrombocytes identified using monoclonal antibodies against thrombocytes of the carp. As is the case with rgTPO, rcTPO with rcKITLA has demonstrated an effect on the formation of cells identified as thrombocytic colonies, thrombocytic burst colonies or thrombocytic/ erythroid colonies (12). Based on that research, it is suggested that TPO and c-Mpl are highly conserved molecular regulators of thrombopoiesis in vertebrates which in Osteichthyes, as opposed to mammalian TPO and c-Mpl, have only a very poor ability to generate in vitro proliferation of progenitor cells for other myeloid cells. This is shown for example by, the significant reduction in tpo and $c$-mpl expression that is observed in cultures of primary kidney macrophages (PKMs) of fish $(11,14,42)$. Research into expression of the tpo gene has shown that the main organ of TPO origin in Osteichthyes is the heart but, as is the case with EPO, it may also be the spleen, the liver, the kidneys or the brain $(10-12,14,42)$. In Osteichthyes, thrombocytes can be found in peripheral blood as well as in the head kidney, the thymus and the intestines. Research by Katakura et al. (12) has shown that in the carp, the sources of these cells which develop as part of TPO dependent thrombopoiesis are solely the head and the hind kidneys as these are the main haematopoietic organs in fish, although it has formerly been the spleen that was considered the most thrombopoietic organ as, apart from mature thrombocytes, different stages of development of these cells can be found in the spleen. The proportion of such cells increases vastly after antigenic stimulation with both soluble and other forms of antigens, for example with Aeromonas salmonicida $(5,9,32)$. 


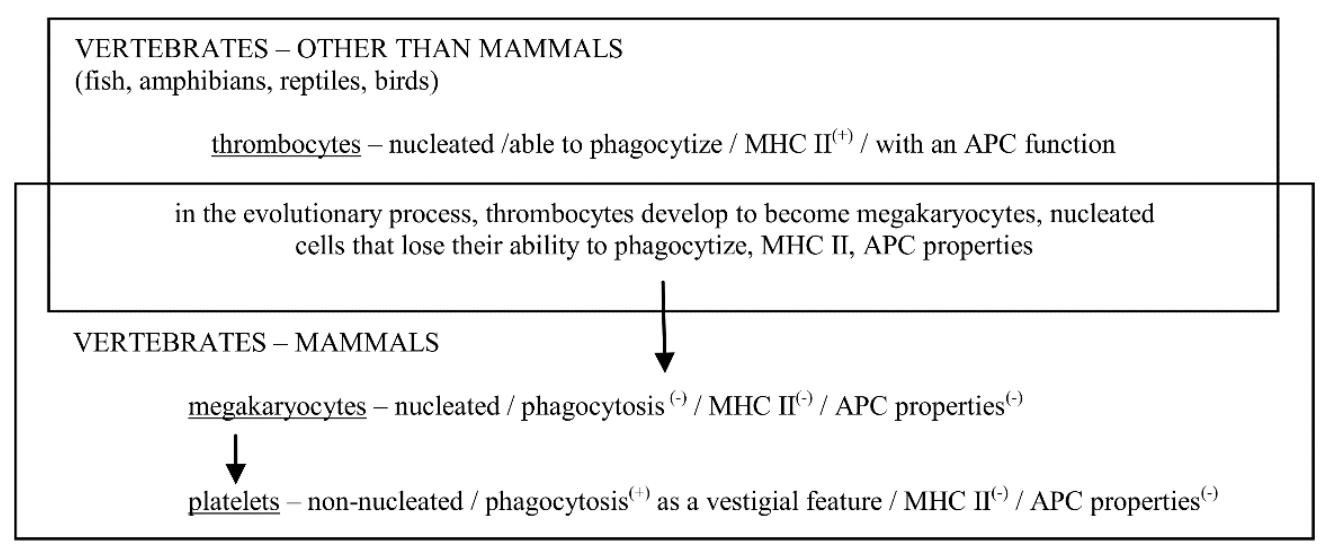

Fig. 2. The possible picture of thrombocyte evolution in non mammalian vertebrates towards formation of platelets in mammalian vertebrates

Table 1. Cytochemical and immunocytochemical properties of thrombocytes compared to properties of neutrophilic granulocytes (PMNc) in Osteichthyes

\begin{tabular}{llll}
\hline $\begin{array}{l}\text { Cytochemical } \\
\text { and immunocytochemical } \\
\text { substances }\end{array}$ & $\begin{array}{l}\text { Thrombocytes } \\
\text { positive }(+), \text { negative }(-), \\
\text { indeterminate }(+-)\end{array}$ & $\begin{array}{l}\text { Polymorphonuclear cells } \\
\text { positive }(+), \text { negative }(-), \\
\text { indeterminate }(+/-)\end{array}$ & References \\
\hline MPO & $(+)$ and $(-)$ & $(+)$ & $3,31,35$ \\
\hline Lysozyme & $(+)$ & $(+)$ and $(+/-)$ & 24 \\
\hline ACP & $(+)$ and $(-)$ & $(+)$ and $(-)$ & 3,35 \\
\hline ALP & $(-)$ & $(+/-)$ & 3,35 \\
\hline$\beta$-glucuronidase & $(-)$ & $(+)$ & 35 \\
\hline ASDE & $(+)$ and $(-)$ & $(+)$ & 31,35 \\
\hline$\alpha$ NAE (ANAE) & $(+)$ and $(-)$ & $(+)$ and $(-)$ & 3,35 \\
\hline$\alpha$ NBE & $(-)$ & $(+)$ & 35 \\
\hline SBB & $(-)$ & $(+)$ & 3,35 \\
\hline PAS & $(+)$ and $(+/-)$ & $(+)$ & $1,3,33,35,43,44,45$ \\
\hline MMP2 & $(-)$ & $(+)$ & 3 \\
\hline MMP9 & $(+)$ and $(-)$ & & 3,5 \\
\hline
\end{tabular}

\section{The morphological and cytochemical properties of thrombocytes in Osteichthyes}

Haematological investigations carried out applying classical methods and flow cytometry with the use of, inter alia, specific monoclonal antibodies (WCL6) have shown that in healthy carp, thrombocytes make up between $30 \%$ and $45 \%$ of the peripheral blood leukocytes (PBLs) $(5,32,36,37)$. In Osteichthyes, these cells are characterised by cigarshaped to ball-shaped forms as well as by the presence of intracellular vacuoles, granular structures that are capable of opening to the surface of the cell via a system of open (surface) microtubules, mitochondria, endoplasmic reticulum, and the presence of a dense, heterochromatic nucleus with an irregular shape, the morphology of which is forced by the peripherally situated, condensed chromatin and the centrally situated euchromatin $(1,3,5,32,36,38$, 45). Phagocytic material has also been seen in the cytoplasm of thrombocytes of various fish species, including the carp, turbot (Psetta maxima), channel catfish (Ictalurus punctatus), black rockfish (Sebastes schlegeli), and rainbow trout (Oncorhynchus mykiss, a synonym of Salmo gairdneri) $(2,3,36,40,41)$. This leads to the conclusion that phagocytosis is one of the functions of thrombocytes. It should also be emphasised that the cigar-shaped form of thrombocytes that turns into a ball-shaped form is associated with the phagocytic and haemostatic activity of these cells, and in particular with the stage involving aggregation and release of components of endothrombocytic granules $(24,25,36)$, and, as research by Jaros et al. (9) showed, the shape-shifting is also a result of antigenic stimulation, during which thrombocytes take the form of cells similar to dendritic cells. Cytochemical examinations of thrombocytes in different species of Osteichthyes, such as Centropomus paralellus (family Centropomidae) (3), Sorubim lima (family Pimelodidae) (1), Brycon orbignyanus (family Characidae) (43), Thunnus maccoyii (family Scombridae) (33), Maccullochella peelii (family Percichthyidae) (35), Oreochromis niloticus (family Cichlidae) (45), and Horabagrus brachysoma (family Bagridae) (31), carried out to check the presence of various substances, showed considerable diversity of data related to specific parameters (Table 1). 
These examinations have revealed the presence of acid phosphatase (ACP) (3) and a positive $(+)$ or weakly positive (+/-) result of activity of non-specific $\alpha$-naphthyl acetate esterase (ANAE) (3), specific naphthol ASD chloroacetate esterase (ASDE) (31), lysozyme (24), myeloperoxidase (MPO) (31) and of a non-enzymatic reaction Periodic-Acid Schiff (PAS) that helps to detect glycogen $(1,3,33,35,43-45)$ and matrix metalloproteinases 9 (MMP9) (5). However, results obtained in other studies $(3,35)$ are not homogenous or repeatable. The negative results of the cytochemical and immunocytochemical examinations of thrombocytes in the species of Osteichthyes named above refer to the occurrence and/or activity of nonspecific $\alpha$-naphthyl butyrate esterase (NBE) and ANAE, ASDE, $\beta$-glucuronidase (35), MPO, alkaline phosphatase (ALP) $(3,35)$, acid phosphatase (ACP) (35), phospholipids detected in a non-enzymatic reaction with Sudan black B (SBB) $(3,35)$, and matrix metalloproteinases (MMP9 and MMP2) (3). All the examined compounds, except for ALP and NBE for which the results obtained are not conclusive, are largely present in the cytoplasmic structures of neutrophilic granulocytes (Table 1) and, in some marker cases, the compounds are found in the cytoplasm of lymphocytes and basophilic granulocytes $(3,35)$. Given their morphological, cytochemical and immunocytochemical properties, besides the haemostatic functions, fish thrombocytes can be grouped with the cells which have a significant impact on the immune response and which demonstrate active involvement in phagocytosis $(1-3$, $31,34,35,45)$. Hydrolases, including ACP and esterase, are active in generating inflammatory conditions and in the immune system cells where they are present in high concentrations, especially in phagocytising cells, and are involved in the decomposition of the substances absorbed by the cells and of foreign particles that occur in the neighbourhood of phagocytising cells. Furthermore, ACP and NBE are regarded as marker enzymes of the lysosomes of phagocytizing cells, particularly monocytes and macrophages $(3,31,35)$, whereas the presence of glycogen in the cytoplasm of neutrophilic granulocytes is considered fundamental to the mechanism of phagocytosis because it is a source of energy required in the process of intracellular destruction and elimination of foreign substances $(1-3,31,35,44,45)$. It should nevertheless be emphasised that, according to Shigdar et al. (35), the panel of enzymes or substances that are biologically active in the phagocytosis in thrombocytes of the Murray cod (Maccullochella peelii peelii), are limited in comparison with neutrophilic granulocytes, with the simultaneous presence of a system of tubules connected to the surface of thrombocytes, may suggest that in such fish cells, the phagocytosis is mechanical, not enzymatic.

\section{Defence functions of thrombocytes in Osteichthyes}

Thrombocytes and microparticles released from thrombocytes (tMP - thrombocyte microparticles) are considered equivalent, in terms of haemostatic and immunological activity, to mammalian platelets and platelet microparticles (pMP) that develop in the process of activation or apoptosis of these cells. Microparticles of thrombocytic origin (tMP) are characterised by the presence of similar surface structures, including surface antigens, e.g. the tissue factor (TF, known as tissue thromboplastin and factor III, cell receptor of plasmatic factor VII) or allb protein which are specific to the cells of their origin $(4,17,18,26)$. Thrombocytes in fish display strong defence potential which is expressed in their phagocytic activity and ability to neutralise and degrade the bacteria absorbed $(4,9,24,37-39,41)$. There is evidence that they make up nearly a half of the population of phagocytising cells among peripheral blood phagocytes (24). Thrombocytic phagocytosis in Osteichthyes is more efficient and effective when the process of absorption affects antigens opsonised with serum components, including the complement (24). Research by Nagasawa et al. (24) showed that the absorption can be ascribed to complement receptor CR3 - CD11-1/CD18-2 isotype, a thrombocyte-specific isotype of subunit CR3 which is an analogue of mammalian surface CR3 that gives the cell an ability to recognise complement-opsonised antigens. The elimination of the effect of complement opsonisation by thermal inactivation of serum confirms the occurrence of the effect in fish (24). It is interesting to note that thrombocytes, unlike the leukocyte fraction, have only one of two isoforms: CD11 or CD18. It has also been observed that the antigens absorbed are eliminated in phagolysosomes in the further stages of thrombocyte absorption, with the involvement of lysozyme and inducible NO synthase (iNOS) (24). Moreover, as opposed to mammalian platelets, thrombocytes in lower vertebrates, including Osteichthyes, have MHC class II molecules on their surface, and the amount of mRNA for MHC class II in immunised rainbow trout increases, which suggests that they can function as cells presenting antigen to T-lymphocytes, just as dendritic cells, macrophages or neutrophilic granulocytes function $(5,9$, $22,24,25)$. Apart from MHC class II transcripts, IL-1 $\beta$ transcript, a very strong pro-inflammatory factor, has also been detected in fish thrombocytes, which confirms that these cells possibly contribute to the inflammation, and CD41 transcript, known as glycoprotein $\mathrm{Ilb}$ or integrin $\alpha \mathrm{IIb}$ which is a specific marker for platelets in mammals and thrombocytes in fish (22-24). Aside from that, the biological functions of fish thrombocytes, such as phagocytic activity and its mechanism are still open to doubt, especially when compared to the well-understood properties of classical phagocytic cells, also those in Osteichthyes. In the case of classical phagocytic cells, the phagocytosis reaction develops as a result of recognition of molecular patterns related to the pathogen 
(PAMP) and opsonins, including immunoglobulins or complement components, and of the effect of selected inflammatory cytokines, such as interferon gamma (IFN $\gamma$ ) and the tumour necrosis factor (TNF) that intensify this process (25). According to Nagasawa et al. (24), it may be assumed that the phagocytosis in fish thrombocytes is similar to that in professional phagocytes. These authors also point to the significance of thrombocyte phagocytosis with regard to the number of these cells, which make up the second largest fraction of peripheral blood cells in fish after erythrocytes, and in view of the fact that among the phagocytising cells in peripheral blood of these animals, thrombocytes made up nearly a half of the cells demonstrating the reaction of antigen absorption. Furthermore, phagocytising and antigen-burdened thrombocytes can also be found in the spleen and kidneys, which indicates a possible contribution of thrombocytes to the transport of antigens to lymphoid tissues and to the generation of further immune response stages, such as adaptive immunity (24). The mechanism of induction of phagocytosis of thrombocytes in the carp strongly correlates with activity of the factors released by leukocytes, particularly those stimulated by lipopolysaccharide (LPS) from Escherichia coli $\mathrm{O} 55$ and phorbol 12-myristate 13acetate (PMA) which are present in the existential environment of thrombocytes (25). Nagasawa et al. (25) have shown that under such conditions, thrombocytes' ability to phagocytise latex particles was higher compared to the phagocytic activity of these cells in a mixed reaction with non-stimulated HB8 leukocytes (a thrombocyte-free fraction) or thrombocytes in the form of a purified fraction $\left(\mathrm{HB}^{+}\right)$. It has also been demonstrated that the inductive impact of the supernatant liquid of HB8- leukocytes on thrombocyte ability to phagocytise is also expressed in a higher proportion of absorbing cells in a reaction with opsonised antigens. The authors (25) assessed in their study the impact of different stimulating factors on thrombocyte absorbability. The factors included collagen, adenosine diphosphate (ADP), bovine thrombin, LPS, and PMA. The assessment concluded that the factors generating the haemostatic functions of these cells have no impact on their phagocytic activity, thus confirming that the phagocytic activity of thrombocytes in Osteichthyes and the involvement of these cells in the immune response development are induced by factors released by the leukocytes activated by on inflammatory process or infection. In the light of these data, it may be concluded that thrombocytes in Osteichthyes are fully capable of recognising opsonised antigens, have killing properties and an ability to influence the development of both innate and adaptive immune responses. They are therefore the "real phagocytes" and can be regarded as belong among the essential cell mediators that activate immune mechanisms $(24,25)$. It has been proved (5) that healthy carp show expression of a large number of genes coding biologically active substances (Table 2) that are crucial for the immune system function.

The finding confirms the important role of thrombocytes in this regard. The expressed genes (Table 2) include the P-selectin gene, pro-inflammatory mediator genes (ill $\beta$, illr1, il6a, il6b, tnf $\alpha$, ifn $\gamma 2$, inos, mmp9, p35 and $p 40 c$ ), anti-inflammatory mediator genes (illo, socs3_1\&2 and socs3_3\&4), chemokine genes, (cxcls 12 and cxca_ll) chemokine receptor genes (cxcrl and $c x c r 2)$, MHC protein-coding genes (dab1/2 and $d a b 3 / 4$ ), and TLR (toll-like) receptors (tlr1, tlr2, tlr5, tlr7, tlr $8 a, t l r 8 b, t l r 9$ and $t l r 20$ ). The expression of the 35 and $p 40 c$ genes confirms the presence of IL12, a substance specific to professional antigen-presenting cells (APCs), in Osteichthyes. Among the three forms of the p40 pro-inflammatory mediators (p40a-c) identified in the carp by Huising et al. (8), in a study by Fink et al. (5) only the $p 40 c$ gene showed expression. No expression of the $p 40 a$ and $p 40 b$ genes or of other genes coding substances important for the development of the immune response was detected. Fink et al. (5) did not detect any expression of il11, p19 and tlr3.1, tlr3.2, tlr4.1, tlr4.2. So, their study has not confirmed the likelihood of the presence of IL23 in the carp, with subunits of the p40 and p19 pro-inflammatory mediators, the sources of which are APCs, as is the case with IL12. It is useful to highlight the fact that TLRs are membrane receptors PRRs which allow for recognition of PAMP microbial antigen patterns and generate the development of innate and adaptive immune responses. The group of important TLRs which are found in fish and which recognise bacterial antigen patterns includes TLR1 and TLR2 that recognise Gram-positive bacterial patterns, TLR4 that recognise Gram-negative bacterial patterns, and TLR5 that recognise flagellin, a flagellar protein. There is evidence that among TLRs recognising viral antigen patterns in fish, TLR7 and TLR8 that recognise single-stranded RNA (ssRNA) show expression, and that there is the TLR9 receptor that recognises the CpG dinucleotide sequences in DNA of bacteria, viruses, and parasites inducing, inter alia, the synthesis of IFN- $\gamma$, TNF- $\alpha$, and IL-12 (5). Complementary DNA (cDNA) screening of different types of cells of the carp revealed expression of the tril gene and the presence of the TRIL additional molecule (a TLR4 interactor with leucine-rich repeats), a component of the TLR4 complex with leucine-rich repeats that contains, apart from the 13 leucine domains, a fibronectin domain and a transmembrane domain, as is the case with mammals. Functionally, it is seen as one of the TLR4 and TLR3 signalling components (30). It is also worth pointing out that high expression of the tril gene was found in carp muscles and skin but the highest was seen in endothelial cells and thrombocytes, as is the case with cerebral cells, and also important to emphasize that bacterial infection, parasitic invasion or LPS stimulation did not affect the expression strength in this gene (30). 
Table 2. Properties/characteristics of immunological importance, found in thrombocytes of Osteichthyes

\begin{tabular}{|c|c|c|}
\hline Property/characteristics & Biological function & References \\
\hline MHC II (dab1/2, dab3/4) & $\begin{array}{l}\text { proteins responsible for antigen presentation to } \\
\text { T-lymphocytes }\end{array}$ & $5,9,24$ \\
\hline MHC Ia, MHC IIB & & 22 \\
\hline$\beta 2 \mathrm{~m}, \mathrm{LMP}, \mathrm{TAP} 1, \mathrm{TAP} 2$ & $\begin{array}{l}\text { molecules responsible for antigen processing } \\
\text { and presentation }\end{array}$ & \\
\hline P-selectin (CD62P) & adhesion molecule & 5,8 \\
\hline IL1 $\beta$, IL1r1, IL6a, IL6b, IFN $\gamma 2$, & pro-inflammatory mediators & 5 \\
\hline p35, p40c (IL12) & & 5,8 \\
\hline $\mathrm{p} 40 \mathrm{a}, \mathrm{p} 40 \mathrm{~b}$ & & 8 \\
\hline IL1 $\beta$, iNOS & & 5,24 \\
\hline $\mathrm{TNF} \alpha$ & & 5,22 \\
\hline IL10, SOCS3 1\&2, SOCS3 3\&4 & anti-inflammatory mediators & 5 \\
\hline CXCL8_L2, CXCA_L1 & $\begin{array}{l}\text { chemokines (CXC), chemotactic cytokines, a } \\
\text { group of proteins that stimulate the motion of } \\
\text { leukocytes and control their migration from } \\
\text { blood to tissues }\end{array}$ & \\
\hline CXCR1, CXCR2 & $\begin{array}{l}\text { chemokine receptor (CXCR) activates the cell } \\
\text { response after addition of a suitable } \\
\text { chemokine. }\end{array}$ & \\
\hline CXCR7, CXCR4 & & 22 \\
\hline $\begin{array}{l}\text { TLR1, TLR2, TLR5, TLR7, TLR8a, } \\
\text { TLR8b, TLR9, TLR20 }\end{array}$ & $\begin{array}{l}\text { PRRs (pattern recognition receptors) which } \\
\text { allow for recognition of PAMP microbial } \\
\text { antigen patterns and for initiation of non- } \\
\text { specific and specific responses. }\end{array}$ & 5 \\
\hline TLR4 & & 30 \\
\hline LMO2 & $\begin{array}{l}\text { a highly conserved protein playing a key role } \\
\text { in the haematopoietic process }\end{array}$ & 14 \\
\hline GATA1 & $\begin{array}{l}\text { a transcription factor, crucial for development } \\
\text { of specific blood cell types from their } \\
\text { precursor cells, necessary for the maturation } \\
\text { of, i.a., megakaryocytes in mammals }\end{array}$ & \\
\hline c-Mpl & $\begin{array}{l}\text { a receptor for thrombopoietin, a } \\
\text { megakaryocyte receptor of thrombopoietin in } \\
\text { mammals }\end{array}$ & \\
\hline $\begin{array}{l}\text { CD11/CD18 } \\
\text { (isotype CD11-1/CD18-2) }\end{array}$ & $\begin{array}{l}\text { an analogue of complement receptor } 3 \text { (CR3) } \\
\text { in mammals, giving the cell an ability to } \\
\text { recognise complement-opsonised antigens }\end{array}$ & 24 \\
\hline CD41 & $\begin{array}{l}\text { membrane proteins (a component of integrin } \\
\alpha \mathrm{IIb} / \beta 3, \mathrm{CD} 41 / \mathrm{CD} 61 \text { ), specific thrombocyte } \\
\text { markers in different fish species, markers used } \\
\text { to identify megakaryocytic precursors, platelets } \\
\text { and megakaryocytes in mammals }\end{array}$ & $14,17,24,29,42$ \\
\hline CD61 & & 29 \\
\hline CD42a & $\begin{array}{l}\text { active molecule, known as GPIX, is expressed } \\
\text { on megakaryocytes and platelets in the process } \\
\text { of platelet aggregation in mammals }\end{array}$ & 22 \\
\hline $\mathrm{TF}$ & $\begin{array}{l}\text { tissue factor, a transmembrane protein and cell } \\
\text { receptor of plasmatic factor VII, is involved in } \\
\text { the immune response regulation }\end{array}$ & 26 \\
\hline
\end{tabular}

The presence of the TRIL molecule has also been detected in other fish species, such as the Atlantic cod (Gadus morhua), the three-spined stickleback (Gasterosteus aculeatus), and the Japanese puffer (Takifugu rubripes) (30). The presence of TLRs on the surface of fish thrombocytes reinforces the conviction that these cells take part in innate immune mechanisms and, as has been proven, in processes connected with adaptive immunity and may play a direct role in the protection of the host against infection, just as is the case with other leukocytes (4). Hence, on the basis of research to date, thrombocytes of Osteichthyes should be recognised as specialised immune cells conditioning the innate immune mechanism and playing an important role in influencing the adaptive immune mechanisms. This is reflected in the level and scope of immune activity in Osteichthyes, supported by an increased proportion of thrombocytes as a result of antigenic stimulation, morphological changes of thrombocytes to forms specific to dendritic cells after antigenic stimulation, and by the presence of surface structures and cytokines released through, TLR gene expression (detection of pathogens), MHC class II protein-coding genes (antigen presentation), and proinflammatory cytokines that are important for the shaping and development of innate and adaptive immunity, as demonstrated by a number of studies $(4,5,9,22,24,25)$. 
Conflict of Interests Statement: The authors declare that there is no conflict of interests regarding the publication of this article.

Financial Disclosure Statement: The article was financed by the Department of Microbiology at the University of Szczecin.

Animal Rights Statement: None required.

\section{References}

1. Bianchi M.B., Jerônimo G.T., Pádua S.B., Satake F., Ishikawa M.M., Tavares-Dias M., Martins M.L.: The hematological profile of farmed Sorubim lima: reference intervals, cell morphology and cytochemistry. Vet Arhiv 2014, 84, 677-690.

2. Burrows A.T., Fletcher T.C., Manning M.J.: Haematology of the turbot, (Psetta maxima, L.): ultrastructural, cytochemical and morphological properties of peripheral blood leucocytes. J Appl Ichthyol 2001, 17, 77-84.

3. da Silva W.F., Egami M.I., Santos A.A., Antoniazzi M.M., Silva M., Gutierre R.C., Paiva M.J.R.: Cytochemical, immunocytochemical, and ultrastructural observations on leukocytes and thrombocytes of fat snook (Centropomus parallelus). Fish Shellfish Immunol 2011, 31, 571-577.

4. Ferdous F., Scott T.R.: A comparative examination of thrombocyte/platelet immunity. Immunol Letters 2015, 163, 32-39.

5. Fink I.R., Ribeiro C.M., Forlenza M., Taverne-Thiele A., Rombout J.H., Savelkoul H.F., Wiegertjes G.F.: Immunerelevant thrombocytes of common carp undergo parasite-induced nitric oxide-mediated apoptosis. Dev Comp Immunol 2015, 50, 146-154.

6. Glass T.J., Lund T.C., Patrinostro X., Tolar J., Bowman T.V., Zon L.I., Blazar B.R.: Stromal cell-derived factor-1 and hematopoietic cell homing in an adult zebrafish model of hematopoietic cell transplantation. Blood 2011, 118, 766-774.

7. Hill D.J., Rowley A.F.: Are integrins involved in the aggregatory and phagocytic behaviour of fish haemostatic cells? J Exp Biol 1998, 201, 599-608.

8. Huising M.O., van Schijndel J.E., Kruiswijk C.P., Nabuurs S.B., Savelkoul H.F., Flik G., Verburg-van Kemenade B.M. The presence of multiple and differentially regulated interleukin12 p40 genes in bony fishes signifies an expansion of the vertebrate heterodimeric cytokine family. Mol Immunol 2006, 43, 1519-1533. doi: 10.1016/j.molimm.2005.10.010.

9. Jaros J., Korytar T., Huong D.T., Weiss M., Köllner B.: Rainbow trout (Oncorhynchus mykiss) thrombocytes are involved in MHC II dependent antigen presentation. Fish Shellfish Immunol 2013, 34, 1657.

10. Katakura F., Katzenback B.A., Belosevic M.: Molecular and functional characterization of erythropoietin receptor of the goldfish (Carassius auratus L.). Dev Comp Immunol 2014, 45 , 191-198.

11. Katakura F., Katzenback B.A., Belosevic M.: Recombinant goldfish thrombopoietin up-regulates expression of genes involved in thrombocyte development and synergizes with kit ligand A to promote progenitor cell proliferation and colony formation. Dev Comp Immunol 2015, 49, 157-169.

12. Katakura F., Sugie Y., Hayashi K., Nishiya K., Miyamae J., Okano M., Nakanishi T., Moritomo T.: Thrombopoietin (TPO) induces thrombocytic colony formation of kidney cells synergistically with kit ligand A and a non-secretory TPO variant exists in common carp. Dev Comp Immunol 2018, 84, 327-336. doi.org/10.1016/j.dci.2018.03.005.
13. Katzenback B.A., Karpman M., Belosevic M.: Distribution and expression analysis of transcription factors in tissues and progenitor cell populations of the goldfish (Carassius auratus L.) in response to growth factors and pathogens. Mol Immunol 2011, 48, 1224-1235.

14. Katzenback B.A., Katakura F., Belosevic M.: Goldfish (Carassius auratus L.) as a model system to study the growth factors, receptors and transcription factors that govern myelopoiesis in fish. Dev Comp Immunol 2016, 58, 68-85.

15. Kawamoto H., Ikawa T., Masuda K., Wada H., Katsura Y.: A map for lineage restriction of progenitors during hematopoiesis: the essence of the myeloid-based model. Immunol Rev 2010, 238, 23-36.

16. Kawamoto H., Katsura Y.: A new paradigm for hematopoietic cell lineages: revision of the classical concept of the myeloidlymphoid dichotomy. Trends Immunol 2009, 30, 193-200.

17. Khandekar G., Kim S., Jagadeeswaran P.: Zebrafish Thrombocytes: Functions and Origins. Adv Hematology 2012, ID 857058, doi.org/10.1155/2012/857058.

18. Kim S., Carrillo M., Radhakrishnan U.P., Jagadeeswaran P.: Role of zebrafish thrombocyte and non-thrombocyte microparticles in hemostasis. Blood Cell Mol Dis 2012, 48, 188-196.

19. Kobayashi I., Katakura F., Moritomo T.: Isolation and characterization of hematopoietic stem cells in teleost fish. Dev Comp Immunol 2016, 58, 86-94.

20. Kobayashi I., Moritomo T., Ototake M., Nakanishi T.: Isolation of side population cells from ginbuna carp (Carassius auratus langsdorfii) kidney hematopoietic tissues. Dev Comp Immunol 2007, 31, 696-707.

21. Kobayashi I., Saito K., Moritomo T., Araki K., Takizawa F., Nakanishi T.: Characterization and localization of side population (SP) cells in zebrafish kidney hematopoietic tissue. Blood 2008, 111, 1131-1137.

22. Köllner B., Fischer U., Rombout J.H.W.M., Taverne-Thiele J.J., Hansen J.D.: Potential involvement of rainbow trout thrombocytes in immune functions: a study using a panel of monoclonal antibodies and RT-PCR. Dev Comp Immunol 2004, 28, 1049-1062.

23. Lin H.F., Traver D., Zhu H., Dooley K., Paw B.H., Zon L.I., Handinet R.I.: Analysis of thrombocyte development in CD41GFP transgenic zebrafish. Blood 2005, 106, 3803-3810. doi:10.1182/blood-2005-01-0179.

24. Nagasawa T., Nakayasu C., Rieger A.M., Barreda D.R., Somamoto T., Nakao M.: Phagocytosis by thrombocytes is a conserved innate immune mechanism in lower vertebrates. Front Immunol 2014, 5, 445. doi.org/10.3389/fimmu.2014.00445.

25. Nagasawa T., Somamoto T., Nakao M.: Carp thrombocyte phagocytosis requires activation factors secreted from other leukocytes. Dev Comp Immunol 2015, 52, 107-111.

26. Ning Y.J., Lu X.J., Chen J.: Molecular characterization of a tissue factor gene from ayu: a pro-inflammatory mediator via regulating monocytes/macrophages. Dev Comp Immunol 2018, $84,37-47$

27. Nombela I., Puente-Marin S., Chico V., Villena A.J., Carracedo B., Ciordia S., Mena M.C., Mercado L., Perez L., Coll J., Estepa A.: Identification of diverse defense mechanisms in trout red blood cells in response to VHSV halted viral replication. F1000 Research, 2017, 6, 1958. doi: 10.12688/f1000research.12985.1.

28. Ortega-Villaizan M.D.M.: The role of red blood cells in the immune response of fish. https://www.frontiersin.org/researchtopics/6573/the-role-of-red-blood-cells-in-the-immune-responseof-fish.

29. Passer B.J., Chen C.H., Miller N.W., Cooper M.D.: Catfish thrombocytes express an integrin-like CD41/CD61 complex. Exp Cell Res 1997, 234, 347-353.

30. Pietretti D., Spaink H.P., Falco A., Forlenza M., Wiegertjes G.F.: Accessory molecules for Toll-like receptors in Teleost fish. Identification of TLR4 interactor with leucine-rich repeats (TRIL). Mol Immunol 2013, 56, 745-756. 
31. Prasad G., Charles S.: Haematology and leucocyte enzyme cytochemistry of a threatened yellow catfish Horabagrus brachysoma (Gunther 1864). Fish Physiol Biochem 2010, 36, 435-443.

32. Rombout J.H.W.M., Koumans-van Diepen J.C.E., Emmer P.M., Taverne-Thiele J.J., Taverne N.: Characterization of carp thrombocytes with specific monoclonal antibodies. J Fish Biol 1996, 49, 521-531.

33. Rough K.M., Nowak B.F., Reuter R.E.: Haematology and leukocyte morphology of wild caught Thunnus maccoyii. J Fish Biol 2005, 66, 1649-1659.

34. Shigdar S., Cook D., Jones P., Harford A., Ward A.C.: Blood cells of Murray cod Maccullochella peelii peelii (Mitchell). J Fish Biol 2007, 70, 973-980.

35. Shigdar S., Harford A., Ward A.C.: Cytochemical characterisation of the leucocytes and thrombocytes from Murray cod (Maccullochella peelii peelii, Mitchell). Fish Shellfish Immunol 2009, 26, 731-736.

36. Stosik M.: Morphology and phagocytic activity of carp's thrombocytes, Cyprinus carpio L. Med Weter 1993, 49, 184-186.

37. Stosik M.: Thrombocyte number and their phagocytic activity in carp (Cyprinus carpio L.) of different age. Med Weter 1995, 51, 621-623.

38. Stosik M., Deptuła W.: Thrombocytes of fish. Med Weter 1992, 48, 556-558.

39. Stosik M., Deptuła W.: Studies on selected protective functions of thrombocytes and neutrophilic granulocytes in healthy and sick carp. Pol J Vet Sci 2000, 3, 219-225.
40. Stosik M., Deptuła W., Trávniček M.: Studies on number and on ingesting ability of thrombocytes in sick carps (Cyprinus carpio L.). Vet Med-Czech 2001, 46, 12-16.

41. Stosik M., Deptuła W., Trávniček M., Baldy-Chudzik K.: Phagocytic and bactericidal activity of blood thrombocytes in carps (Cyprinus carpio). Vet Med-Czech 2002, 47, 21-25.

42. Svoboda O., Stachura D.L., Machoňová O., Pajer P., Brynda J., Zon L.I., Traver D., Bartůněk P.: Dissection of vertebrate hematopoiesis using zebrafish thrombopoietin. Blood 2014, 124, 220-228.

43. Tavares-Dias M., Moraes F.R.: Morphological, cytochemical, and ultrastructural study of thrombocytes and leukocytes in neotropical fish, Brycon orbignyanus Valenciannes, 1850 (Characidae, Bryconinae). J Submicrosc Cytol Pathol 2006, 38, 209-215.

44. Tavares-Dias M., Ono E.A., Pilarski F., Moraes F.R.: Can thrombocytes participate in the removal of cellular debris in the blood circulation of teleost fish? A cytochemical study and ultrastructural analysis. J Appl Ichthyol 2007, 23, 709-712.

45. Ueda I.K., Egami M.I., Sasso W.S., Matushima E.R.: Cytochemical aspects of the peripheral blood cells of Oreochromis (Tilapia niloticus. Linnaeus, 1758) (Cichlidae, Teleostei): Part II. Brazilian J Vet Res Animal Sci 2001, 38, 273-277.

46. Zimmerman L.M., Vogel L.A., Edwards K.A., Bowden R.M.: Phagocytic B cells in a reptile. Biol Lett 2010, 6, 270-273. doi:10.1098/rsbl.2009.0692. 